\title{
GOD, EVIL, AND ALVIN PLANTINGA ON THE FREE-WILL DEFENCE
}

\section{CIRO DE FLORIO \& ALDO FRIGERIO}

\author{
Università Cattolica Del Sacro Cuore - Milano
}

\begin{abstract}
In this paper we will give a critical account of Plantinga's well-known argument to the effect that the existence of an omnipotent and morally perfect God is consistent with the actual presence of evil. After presenting Plantinga's view, we critically discuss both the idea of divine knowledge of conditionals of freedom and the concept of transworld depravity. Then, we will sketch our own version of the Free-Will Defence, which maintains that moral evil depends on the misuse of human freedom. However, our argument does not hinge on problematic metaphysical assumptions, but depends only on a certain definition of a free act and a particular interpretation of divine omniscience.
\end{abstract}

\section{INTRODUCTION}

We share Robert M. Adams' influential view, expressed here:

No-one has contributed more than Alvin Plantinga to the development of an analytical tradition in the philosophy of religion, and his studies of the problem of evil are among his most important contributions to the field. (Adams 1985: 225)

However, we believe that at least one aspect of Plantinga's philosophy of religion, his Free Will Defence (FWD, from now on), ${ }^{1}$ is puzzling. In this paper we will show that Plantinga's argument is based on a set of assumptions which are hard to maintain. Then we will develop another kind of FWD not grounded on Plantinga's metaphysical assumptions and we will discuss some consequences of our view. In particular, section 2 deals with three basic aspects of Plantinga's FWD: the difference between defence and theodicy, the existence of conditionals of freedom and the concept of transworld depravity. These three concepts are critically discussed in section 3. Section 4 sketches out an alternative FWD not based on Plantinga's problematic assumptions.

\footnotetext{
${ }^{1}$ Cf. Plantinga (1967), Plantinga (1974a), Plantinga (1974b), Plantinga (1985).
} 


\section{PLANTINGA'S FREE WILL DEFENCE}

The basic idea of both defences and theodicies based on free will is that evil is a consequence of free human actions and that not even God, even though $\mathrm{He}$ is omnipotent, can remove evil depending on free will. This approach has been criticized from several angles. One of the most interesting objections is advanced in J. L. Mackie's seminal paper Evil and Omnipotence. ${ }^{2}$ Mackie concedes that the existence of free beings is a good worthy of being pursued by God and that some free beings sometimes choose evil. However, Mackie claims, there is no contradiction in the concept of a person who always chooses good. If the existence of morally perfect persons is logically possible, why didn't God actualize these persons? Had he done this he would have preserved freedom without bringing suffering and evil into the world in order to do so.

In a series of papers written over a long period, Plantinga has developed and defended a counter-argument to Mackie's thesis that theistic belief is irrational. Plantinga's idea is that it is not true that an omnipotent God can actualize a state of affairs like that described by Mackie, i.e. a world in which free persons always choose good. Even if this is not explicitly stated by Plantinga, it is important to note from the start that the modality whereby God cannot do something is metaphysical. The three basic points of Plantinga's argument are: the formal structure of the argument (i.e. that it is a defence and not a theodicy) the existence of true conditionals of freedom, and the concept of transworld depravity. We will consider them in this order.

\subsection{Defence and theodicy}

The logical problem of evil concerns the contradiction between two propositions:

(G) An omnipotent, omniscient, and morally perfect God exists

(E) Evil exists

In short, the argument is as follows: $(G)$ and $(E)$ cannot both be true; since $(E)$ is true, $(G)$ must be false. The theist's task is to show that $(G)$ and (E) do not actually contradict each other; this task can be carried out by finding a proposition (L) which is not contradictory to $(G)$ and which, together with $(\mathrm{G})$, implies (E). According to Plantinga, the difference between theodicy and defence consists in the different epistemic statuses

${ }^{2}$ Mackie (1955: 209). 
of (L). If a theodicy is the aim, one must not only show the coherence of $(\mathrm{G})$ and $(\mathrm{L})$, but also defend the truth of (L). On the other hand, a defence need not show the truth of $(\mathrm{L})$ : it is sufficient to argue that $(\mathrm{G})$ and $(\mathrm{E})$ are not contradictory if $(\mathrm{L})$ is true, i.e. that there exists a possible word in which (L), (G), and (E) are all true. ${ }^{3}$ Since a defence need not be committed to the truth of $(\mathrm{L})$ but only to its possibility and coherence with $(\mathrm{G})$, it is a much less demanding task and, as such, more easily feasible.

\subsection{Conditionals of Freedom and Leibniz's Lapse}

To respond to Mackie's objection, a proposition, (L), must be found that is both possible and consistent with $(\mathrm{G})$, and that implies the existence of evil. To do so, Plantinga raises some metaphysical issues. He asks: can God do everything that is logical possible? His answer is no. Among the possible worlds that God cannot actualize are some which involve free human actions. Plantinga's favourite example is the following: suppose that Curley Smith, the Mayor of Boston, is offered a bribe of $\$ 35,000$ by the directory of highways, Smedes. Smith accepts. Smedes wonders whether he could have bought Smith for $\$ 20,000$. We have two different propositions:

(i) If Smedes had offered Smith a bribe of $\$ 20,000$, he would have accepted it.

(ii) If Smedes had offered Smith a bribe of $\$ 20,000$, he would not have accepted it.

(i) and (ii) are usually called counterfactuals because the antecedent describes a situation which did not obtain (i.e. it is false), but which could have obtained. (i) and (ii) make reference to something which could have obtained in the past and which actually did not obtain. However, it is possible to reformulate (i) and (ii) in a way that does not make reference to the past:

(iii) If Smedes were to offer Smith a bribe of $\$ 20,000$, he would accept it.

(iv) If Smedes were to offer Smith a bribe of $\$ 20,000$, he would not accept it

(iii) and (iv) are conditionals of freedom. In a conditional of freedom the antecedent is a logically possible state of affairs, while the consequent is a state of affairs which depends on the agent's free action. Let's fix the following notions: $S$ ' is a complex state of affairs containing every state of

\footnotetext{
${ }^{3}$ Cf. Plantinga (1974a: 28).
} 
affairs in the world prior to Smith's choice. S' contains the offering of the bribe, but neither Smith's possible refusal nor his possible acceptance. Plantinga calls S' a maximal world segment. We might think of it as the history of the world until Smith's choice. Suppose that A is the acceptance of the bribe and $\neg \mathrm{A}$ its refusal. We can outline the situation as in figure 1:

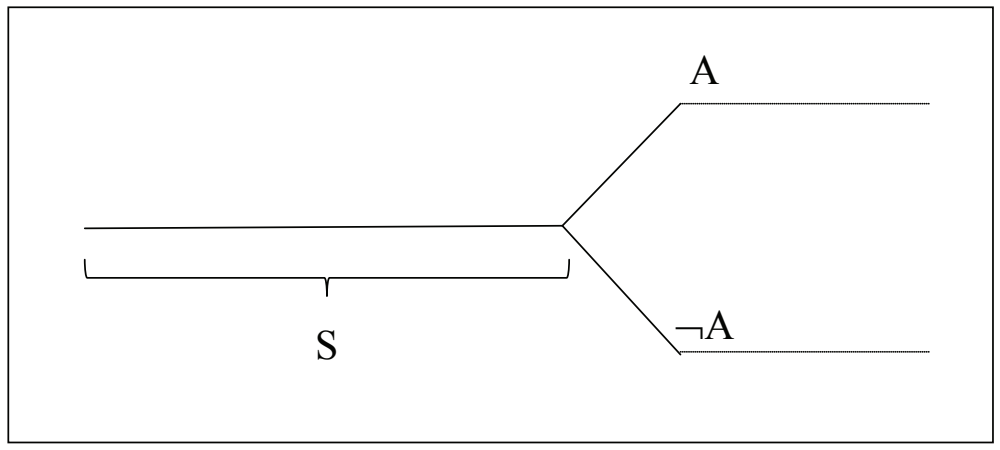

Figure 1

Smith can accept the bribe or not. If he accepts, he actualizes the state of affairs A; otherwise, he actualizes the state of affairs $\neg$ A. Let's call W the world containing the maximal world segment $S^{\prime}+A$ and $W^{\prime}$ the world containing the maximal world segment $S^{\prime}+\neg \mathrm{A}$. Suppose that (iii) is true, i.e. that if $\$ 20,000$ were offered to Smith, he would accept. Then, although $\mathrm{W}^{\prime}$ is a logically possible world, it could not be actualized by God, as we will now explain. In order to actualize W', God must actualize S'. However, given this maximal world segment, Smith would freely choose to accept the bribe. So W, and not W', would be actualized. On the other hand, if God actualizes S' and forces Smith to refuse the bribe, Smith is no longer free; in consequence, God is not actually actualizing $W^{\prime}$ because in $W^{\prime}$ Smith is free to accept or refuse and, in fact, refuses. On the other hand, if (iv) is true (if Smith refuses the bribe), a perfectly symmetrical line of reasoning can be followed. In both cases, there is at least one possible world which God cannot actualize. In sum, Plantinga's argument is that, if free agents are involved, there is some aspect of the world which depends on their choice and not on God's action. Plantinga challenges Leibniz's definition of omnipotence as the possibility of doing everything which is logically possible. In fact, there are possible worlds which God cannot actualize. 


\subsection{Trans-world Depravity}

However, Plantinga has not yet rebutted Mackie's argument. He has only showed that there are possible worlds that God cannot actualize. Plantinga has still to demonstrate that Mackie's possible world, i.e. a world in which free beings always choose good, is one of the worlds that God cannot actualize. To show this Plantinga introduces the concept of transworld depravity, which can be informally defined as follows: a person $p$ suffers from transworld depravity (TD) iff in every possible world in which $p$ exists there is at least one morally significant action for $p$ such that $p$ acts wrongly with respect to that action. Plantinga claims that it is logically possible that someone suffers from TD. However, if this is true, it is also true that it is logically possible that every human being suffers from TD. Indeed Plantinga asserts (1974: 49ff.) that TD might not be a contingent feature of human beings: human beings' essence might suffer from TD. If it were so, TD would not depend on the fact that persons' essences have been actualized in particular real persons. On the contrary, it could be possible that TD characterizes the essences themselves of human beings, i.e. that every human being cannot always go right. This, together with the impossibility of actualizing every logically possible world, is enough to refute Mackie's objection. Although Mackie's world (a world in which only saints exist) is logically possible, because of TD it is also possible that there are always situations in which human beings act wrongly. In the situations in which TD is true, God cannot actualize Mackie's world for the same reason why He cannot actualize a world in which Smith freely refuses the bribe. In sum, Plantinga thinks he has rebutted the atheist's argument that the existence of God is incoherent with the existence of evil. There is a proposition, (L) - God cannot create a world containing only moral good and no moral evil - which is consistent with the existence of God (G) and which, together with $(G)$, implies the existence of evil, (E). Since we are concerned with a defence and not a theodicy, (L) need not be true but only possible.

In the following section, we will see that Plantinga's argument is much more problematic than it might seem at first due to the metaphysical assumptions on which it is based. We believe that, in spite of Plantinga's defence, theism is still under attack. 


\section{DOES PLANTINGA'S FWD WORK?}

\subsection{Middle Knowledge}

Plantinga's FWD is grounded, among other things, on conditionals of freedom. A conditional of freedom says how a free being acts in a certain situation. Plantinga assumes that conditionals of freedom:

(i) have a determinate truth value and some of them are true;

(ii) are known by God, if they are true (and presumably God also knows that false conditionals of freedom are false);

(iii) are not in contradiction with the freedom of human beings.

These assumptions are rather demanding, as we will shortly see. In particular (ii) implies what was called scientia media by Luis de Molina (1535-1600). According to de Molina, God can foresee what a human agent $x$ will do because He knows which conditionals of freedom are true: by actualizing a state of affairs $S^{\prime}$ and by the knowledge of the conditional of freedom 'if $S$ ', then $x$ freely performs A', God foresees that $x$ will freely perform A in S. However, as Adams shows, ${ }^{4}$ it is hard to see how conditionals of freedom can be true. If we assume, as Plantinga does, libertarianism, we must say that the state of affairs $S$ ' is insufficient to determine the choice of $x$. Given $S$ ' there is a possible history of the world in which $S^{\prime} \rightarrow A$ and an alternative history in which $S^{\prime} \rightarrow \neg A$; hence, in the first history $S^{\prime} \wedge A$ is true and in the second one $S^{\prime} \wedge \neg A$ is true.

Craig (2001) claims that the law of the excluded middle must be true also of conditionals of freedom. In consequence, $S^{\prime} \wedge A$ and $S^{\prime} \wedge \neg A$ must both be true or false. Since God is omniscient, He must know which conditionals of freedom are true and, in particular, whether $S^{\prime} \wedge A$ or $\mathrm{S}^{\prime} \wedge \neg \mathrm{A}$ is true. However, it is not clear if the law of excluded middle must hold for conditionals of freedom. In fact, we believe that it is part of libertarianism that certain propositions do not have a truth value. If $x$ is free to do $\mathrm{A}$ or $\neg \mathrm{A}$, then before $x$ 's choice it is neither true nor false that $x$ will do A. Here we sketch out a model that is able to account for this indeterminism. First the model will be applied to the problem of future contingents, then to that of conditionals of freedom. ${ }^{5}$

${ }^{4}$ Cf. Adams (1973) and (1978).

${ }_{5}$ As amply discussed in the literature, for instance by Otte (1987) and O'Connor (1992), it is natural to apply the solution given to the problem of future contingents to conditionals of freedom as well. 
The classical structure of branching time will be assumed, i.e. given a world $w$ and a present time $t_{0}$, there exists only one past history, but many possible future histories.

The moments 'cut' histories, in the sense that more than one history can pass through the same moment. Suppose that in a moment $t_{1}$ such that $t_{1}>t_{0}$ the agent $x$ must choose between $\mathrm{A}$ and $\neg \mathrm{A}$. Since $x$ is free there is at least one future history $h_{1}$ in which $x$ performs $\mathrm{A}$ at $t_{1}$ and at least one different future history $h_{2}$ in which $x$ performs $\neg \mathrm{A}$ at $t_{1}$ (cf. figure 2 ).

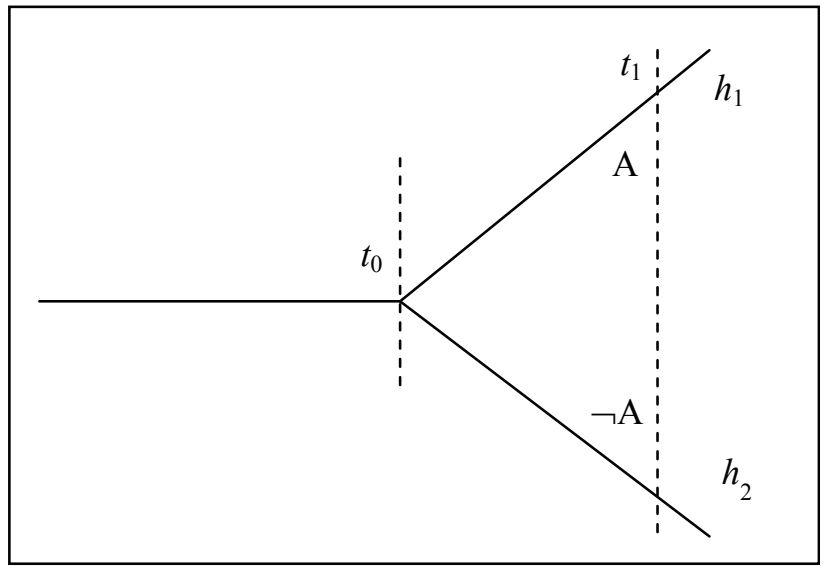

Figure 2

In the branching time model, 'time moves forward': in particular, when the present time is $t_{1}, x$ 's choice is made and one of the histories $h_{1}$ or $h_{2}$ is 'removed'. Suppose that $x$ does A at $t_{1}$ and that history $h_{2}$ is removed. Only history $h_{1}$ 'survives' when the present time is $t_{1}$ (figure 3 ).

Let's assume van Fraassen's supervaluation theory (cf. van Fraassen 1966). We can suppose that a proposition $p$ is evaluated with respect to a time $t$ and to a history $h$ and supervaluated with respect to all histories that pass through $t$. It follows that when the present time is $t_{0}$, it is true that $x$ does $\mathrm{A}$ at $t_{1}$ in $h_{1}$ and false that $x$ does $\mathrm{A}$ at $t_{1}$ in $h_{2}$. However the supervaluation of the proposition ' $x$ does $A$ ' at $t_{1}$ is neither true nor false because there is a history in which the proposition is true and another history in which the proposition is false. The same holds for the proposition ' $x$ does $\neg \mathrm{A}$ '. When time goes on from $t_{0}$ to $t_{1}$ only history $h_{1}$ survives and therefore the proposition ' $x$ does A' becomes supertrue at $t_{1}$ and the proposition ' $x$ does $\neg \mathrm{A}$ ' becomes superfalse at $t_{1}$. 


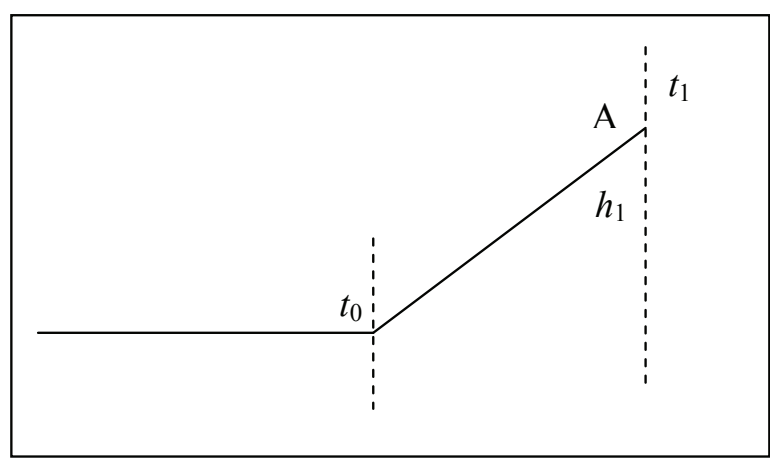

Figure 3

This model accounts for the fact that the proposition ' $x$ does $\mathrm{A}$ at $t_{1}$ ' has no truth value before $x$ 's choice to do $\mathrm{A}$ or $\neg \mathrm{A}$ at $t_{1}$ : when the present time is $t_{0}$, the supervaluation is indeterminate. When $x$ takes a decision to do $\mathrm{A}$, every history in which $x$ does $\neg \mathrm{A}$ is removed and the supervaluation of the proposition becomes true. ${ }^{6}$

The same model can be applied to conditionals of freedom: given a world $w$, let's call S' the state of the world till $t_{0}$ and A the action that $x$ can perform at $t_{1}$. Since the value of the proposition ' $x$ does $\mathrm{A}$ at $t_{1}$ ' is indeterminate before $x$ 's decision to do or not to do A at $t_{1}$, the conditional of freedom S' $\rightarrow$ A has an indeterminate value until $x$ 's decision. This conditional is true in some histories (those in which $x$ does A) and false in other histories (those in which $x$ does $\neg$ A), so until $x$ 's decision there is no way to give a truth value to the conditional of freedom. The conditional becomes true or false after $x$ 's decision, too late to be of use for God when deciding which world to actualize.

Molinists might claim that conditionals of freedom are true or false because, given S', there exists only one history of the world. In this history $x$ does $\mathrm{A}$ or $\neg \mathrm{A}$ and God knows this unique history. However, this does not seem to be compatible with libertarianism because libertarianism

${ }^{6}$ This model has the advantage of preserving logical truths: for instance, the proposition 'at $t_{1}(p \vee \neg p)$ ' is supervaluated true even when the present time is $t_{0}$ because $p \vee \neg p$ is true in every history passing through $t_{1}$. In the same way, 'at $t_{1}(p \wedge \neg p)$ ' is superfalse. Øhrstrøm (2011) objects that 'it seems odd that a disjunction could be true when neither of the disjuncts is true, and a conjunction false when neither of the conjuncts is false. However, it seems to us that just the opposite is true: if $x$ is free, it is indeterminate today if $x$ will do A tomorrow, but it is not indeterminate today if $x$ will do $\mathrm{A}$ or $\neg \mathrm{A}$ tomorrow. In the same way, we know today that $\mathrm{x}$ will not do both $\mathrm{A}$ and $\neg \mathrm{A}$ tomorrow. 
implies that S' does not determine $x$ 's action, so that many histories of the world are compatible with S.

Alternatively, Molinists can state that there are many future histories, but that one of them is the unique 'true history'? The position held by these Molinists is similar to that of thin red line theorists, who claim that a 'true future' exists among contingent futures. However, Thomason (1970) and MacFarlane (2003) have questioned the compatibility of the thin red line theory with the idea that the future is really indeterminate. If one possible world history is the true history, it is not indeterminate at $t_{0}$ which the future history of the world is: the other histories of the world do not seem to be real possibilities open to the agent. In the model we presented, the "true future" is determined only when the agent decides, i.e. only when the future is no longer future, but present. Usually, thin red line theorists maintain that the true future is the future which will happen. However, in our model, when the present is $t_{0}$, there is not a unique future that will happen and therefore no 'true' future. On the contrary, there are many possible futures, none of which is (yet) the future which will happen. Only when time moves forward to $t_{1}$, does the proposition that $x$ does $\mathrm{A}$ at $t_{1}$ receive a truth value.

It might be objected that the thesis that conditionals of freedom have no truth value implies that God does not foresee human actions and that therefore God is not omniscient. Answering this objection in detail goes beyond the aims of this paper. Here it will be sufficient to note that, besides Molinism, there are other ways to reconcile divine foreknowledge and human freedom which do not presuppose the truth of conditionals of freedom. We think that one of the most attractive theories affirms that God is external to time and that He has not actual foreknowledge of human actions, but only knowledge of them. This solution has not been exempt from criticisms, ${ }^{8}$ but, as far as the problem we are dealing with here is concerned, it allows us to assert that God knows every human choice without having a scientia media.

\subsection{Transworld Depravity}

The third aspect, which we analyzed, of Plantinga's FWD is Transworld Depravity, that is a property that all human beings might possess and that

7 This seems to be the position defended in Otte (1987) and Gaskin (1998).

${ }^{8}$ Cf. Zagzebski (1991). 
forces them to act wrongly at least on some occasions. In our opinion TD encounters three kinds of problem:

I. Let's fix some terminology in order to face the question:

Let's introduce an infinite set of individual variables $(x, y, z, \ldots)$ and three primitive predicates:

$\begin{array}{ll}F x: & x \text { is free } \\ E y: & y \text { is an evil action } \\ D(x, y): & x \text { does } y \\ \text { TD can be defined as follows: } \\ \operatorname{TD}(x) \leftrightarrow \square(F x \rightarrow \exists y(E y \wedge D(x, y)))\end{array}$

An individual $x$ is transworld depraved iff in every possible world in which $x$ is free there is an evil action committed by $x$. For convenience the following definition is introduced:

$$
M x \leftrightarrow(F x \wedge \exists y(E y \wedge F(x, y)))
$$

Then a person $x$ suffers from TD iff necessarily $M x$.

The first thing to note is that TD is a property that implies a necessity. Since Plantinga develops a defence and not a theodicy, he says that it suffices that TD is possible:

$$
\diamond \exists x \square M(x)
$$

However, this is not an innocent move, as we will see shortly. It is remarkable that neither Plantinga in his presentation of FWD nor his commentators in the following debate have specified the modal system in which they are working. This is peculiar in light of the fact that TD has a clear modal status. It is likely that, since logical and metaphysical modalities are involved, a good candidate is S5. ${ }^{9}$ Now, since Plantinga assumes that $\diamond \exists x \square M(x)$ must be true in the actual world, there must exist a possible world $w$ accessible from the actual world in which $\exists x \square M(x)$ is true. Hence, $w$ contains at least one person who suffers from TD. If $\exists x \square M(x)$ is true in $w$, it follows that $\square \exists x M(x)$ is also true in that world, that is in every world accessible from $w$ it is true that $\exists x M(x)$. However, since the relation of accessibility is symmetrical in $S 5, \exists x M(x)$ will be

9 The modal system S5 is characterized by two axioms: the first declares that if something is necessary, then it is also actual ( $\square \mathrm{A} \rightarrow \mathrm{A}$ ); the second that if something is possible, then it is also necessary that it is possible $(\diamond A \rightarrow \square \vee A)$. This system calls for models characterized by a very strong accessibility relation, apt to represent the notions of logical and, perhaps, metaphysical possibility. 
true in the actual world. From an 'innocent' commitment to a possibility $(\diamond \exists x \square M(x))$ the actuality of $\exists x M(x)$ follows. Of course something like this does not always follow in S5, but only when a necessary property is involved. ${ }^{10}$

There are at least two consequences for Plantinga's FWD: firstly, Plantinga's argument seems to be a theodicy rather than a defence. Indeed, he cannot assume only that it is possible that people are evil but he has to affirm that all people are actually evil. In formal terms, Plantinga is compelled to assume $\left(^{*}\right)$ :

(*) $\forall x \square M x$

If $\left(^{*}\right)$ is the proposition (L) which makes the existence of God compatible with the existence of evil, then what Plantinga is actually stating is the truth of (L) and not only its possibility. Since Plantinga's argument requires the truth of $(\mathrm{L})$, it is a theodicy, against his own intentions. As such, his position is much more demanding and more vulnerable, as we will see in a moment.

Secondly, it is not clear in what sense people affected by TD are still free. If we know a priori that the space of possible choices is limited (not logically but perhaps metaphysically) by this particular feature of human soul, we should conclude that human agents are not totally free, inasmuch as they are affected by TD. If TD is a necessary feature, how could Mackie's hypothesis still be available? It should be noted that this is not directly concerned with God's being unable to actualize Mackie's world but with real possibilities, given TD.

II. As we have said before, Plantinga's commitment to the truth of $\left(^{*}\right)$ weakens his position. It could be asked, for instance, on what TD depends. There are at least two alternatives: human beings are corrupted because their ontological constitution is corrupted or they are corrupted because of freedom itself. Both ways, however, seem to be puzzling. The first option has a venerable history and it might be defended with reference to the fundamental metaphysical distinction between the infinite Creator and a finite creature. However, lacking further metaphysical principles, this approach is not very helpful; if this essential corruption of human beings depends on our very constitution, why weren't we created in

${ }^{10}$ More generally, in S5 the following 'reductions' hold: $\square \triangleright \ldots \square \mathrm{A} \rightarrow \square \mathrm{A}$ and $\diamond \square \ldots \diamond \mathrm{A} \rightarrow \diamond \mathrm{A}$. Less formally in S5 there are only two modalities: necessity and possibility (of a state of affairs) and iterations can be reduced to these basic modalities. 
a different way? What kind of reason could God advance to explain His choice of actualizing transworld depraved people? Furthermore, if human beings are necessarily corrupted, why did God create human beings and not other free agents, immune from TD?

To make Plantinga's thesis more plausible, the proposition $\left({ }^{*}\right)$ has to be true not only of human beings but of every free agent God could have created. It is of course possible to refer to a metaphysical necessity which presides over the creative power of God, but there is no evident reason why God should be forced to create free beings, who are essentially corrupted. ${ }^{11}$

If we take the second alternative, we state that TD depends on freedom or on freely acting. But, if this is true, why is God immune? That is, why does God, who is free, make only right choices? A tentative answer might specify the difference between our freedom and God's, but the point is that, lacking any account of it, transworld depravity seems to be too strong a concept and to involve unjustified premises.

III. Finally - as a third criticism - for Plantinga's argument it is not enough that some people suffer from TD but it is necessary that all people (or, better, the essences of all people) possibly suffer from TD. ${ }^{12}$ In other words, Plantinga seems to state something as the following:

$(\mathrm{Gen}) \diamond \mathrm{TD}\left(x_{1}\right), \diamond \mathrm{TD}\left(x_{2}\right), \diamond \mathrm{TD}\left(x_{3}\right), \diamond \mathrm{TD}\left(x_{4}\right), \ldots$ therefore $\diamond \forall x \operatorname{TD}(x)$

If it is possible that person $x_{1}$ is transworld depraved and if it is possible that person $x_{2}$ is transworld depraved and if it is possible that person $x_{3}$ is transworld depraved and so on, then it is possible that all people are transworld depraved. It is clear enough that this inference, in this form, is not valid. Let us consider, for instance, a case of murder: surely, it is possible that the first accused is innocent, and the same holds for the second, the third and so on. However, obviously, it is not possible that all people are innocent, since there must be a culprit. Alternatively, let us take a similar argument, aiming to demonstrate that there exists no possible world (viz. it is not logically possible) where Charles and Joanna get married: is there one world conceivable in which Charles and Joanna don't get married? Of course. Are there also two such worlds conceivable?

${ }^{11}$ It might be possible to postulate a metaphysical axiom which states that every being created by God is finite or, at any rate, different in some aspect from its Creator. Of course, the task then is to find independent reasons to justify this assumption.

12 Plantinga (1974: 48). 
Absolutely. Three? Yes. So, is it therefore reasonable to believe that in every possible world they don't get married? Not at all! ${ }^{13}$

So reformulated, Plantinga's argument does not seem so convincing; but there is a reason whereby Plantinga doesn't consider this aspect problematic: this sort of inference is valid, or at least plausible, insofar as the property which is predicated of all possible individuals is an essential feature; otherwise, if it is a contingent property as in the examined cases, the inference is not valid. As a matter of fact, if it were, hypothetically, essential to Charles and Joanna not to get married, then their marriage would not take place in any possible world.

However, if we already assume, ab initio, that the property is essential, then the generalization is plainly valid: if $P$ is essential to individuals $x_{1}, x_{2}, x_{3}, \ldots$ of a certain kind, then $\forall x P x$ holds. This is true even without appeal to any modal notion. To return to the original question, Plantinga maintains that transworld depravity is an essential feature of the human soul; but this, as we have seen before, involves two very strong consequences: firstly, since TD is a necessary feature of human beings, then if it is possible that human beings are transworld depraved, it follows that they are - given modal system S5; secondly, we have seen that all people are corrupted. All this has relevant consequences from a metaphysical and moral point of view; for this reason, Plantinga cannot entrench himself behind the, at first sight, innocent assumption of the logical possibility of transworld depravity.

\section{AN ALTERNATIVE FREE-WILL DEFENCE}

\subsection{Freedom and Evil}

Plantinga's free-will defence is not, however, the only available free-will defence; in particular it is possible to elaborate on the intuition according to which moral evil stems from the free actions pursued by free agents without presupposing Plantinga's problematic assumptions. Here, we try to delineate an argument like this. ${ }^{14}$ The strategy is as follows: first of all, we will establish a few principles that essentially link freedom or better, a certain kind of freedom - with the possibility to perform

${ }^{13}$ A similar argument is in Howard-Synder and O'Leary-Hawthorne (1998).

14 Our defence shares some intuitions with Pruss (2003). Unlike Pruss, however, we specify the primitive concepts employed and we prove, as theorems, the assumptions of Pruss' work. 
certain actions; then, we will proceed, so to speak, backward, moving from Mackie's objections and trying to defend a more plausible version of FWD, deflating the problematic principles of Plantinga's metaphysics.

Given the nature of FWD, it is crucial what concept of freedom is assumed. Plantinga assumes an incompatibilist view of human free will and this is likely the only way to make sense of FWD. However, according to the incompatibilist approach:

(i) An agent is free when she auto-determines her choices - that is, she is the causal principle of her action.

(ii) An agent is free when she could do otherwise.

The conditions (i) and (ii), although necessary for FWD, are not sufficient; take as an example the following case:

Tom can eat the chocolate cake or the cream cake.

Clearly, to employ the concept of free-will in FWD it is indispensable that this is morally characterized. Moral free-will concerns states of affairs morally characterized, that is good or evil states of affairs. ${ }^{15}$ In this sense, being morally free means being free to perform a right or evil action. So, let us recall the following fundamental relation:

(1) $D(x, \mathrm{~B})$ The agent $x$ does $\mathrm{B}$; $x$ performs the action $\mathrm{B}$

Let us define the derived relation $F$ :

(2) $F(x, B)$ The agent $x$ is free to perform $\mathrm{B}^{16}$

This last relation is connected with the first one. As a matter of fact, if an agent is free to perform the action $B$, it is possible that the agent refrains from performing the action $\mathrm{B}$. Therefore:

(3) $F(x, \mathrm{~B}) \rightarrow \diamond D(x, \neg \mathrm{B})$

Clearly, if an agent is free to perform the action $B$, then that agent can perform the action $B$. So:

(4) $F(x, \mathrm{~B}) \rightarrow \diamond D(x, \mathrm{~B}) \wedge \diamond D(x, \neg \mathrm{B})$

Let us introduce, at this point, the idea of morally free-will:

(5) $F^{\mathrm{M}}(x)$ The agent $\mathrm{s}$ is morally free

Where the predicate of moral freedom is analyzed as follows:

(6) $F^{\mathrm{M}}(x) \leftrightarrow \exists \mathrm{A}(\mathrm{A}$ is evil $\vee \mathrm{A}$ is $\operatorname{good} \wedge F(x, \mathrm{~A}))$

${ }^{15}$ It goes beyond the aims of this work to establish what is meant by 'good state of affairs' and 'bad state of affairs'; the argument we offer is, from the ethical point of view, completely formal.

${ }^{16} F(x, \mathrm{~B})$ could be intended as the abbreviation of $F(x, D(x, \mathrm{~B}))$. 
That is

(7) $F^{\mathrm{M}}(x) \leftrightarrow \exists \mathrm{A}(\mathrm{A}$ is evil $\vee \mathrm{A}$ is good $\wedge \triangleright D(x, \mathrm{~A}) \wedge \diamond D(x, \neg \mathrm{A}))$

What does it mean to say that $\mathrm{s}$ is morally free? It means that she has a moral alternative, she can actualize a right or evil state of affairs.

Now we have the resources to prove the theorem we need for our version of FWD. Given an agent $x$ and an action B

(Theorem) $\neg \diamond D(x, \mathrm{~B}) \rightarrow \neg F(x, \neg \mathrm{B})$

That is, if the agent cannot perform an action, $B$, then she is not even free to refrain from performing B. This is plausible: if I cannot climb Everest, I can't say that I freely refrain from doing so.

This is easy to prove. Let us start from $F(x, \neg \mathrm{B}) \rightarrow \diamond D(x, \mathrm{~B}) \wedge$ $\diamond D(x, \neg \mathrm{B})$. By logic, we have that $\neg(\diamond D(x, \mathrm{~B}) \wedge \diamond D(x, \neg \mathrm{B})) \rightarrow \neg F(x, \neg \mathrm{B})$; by logic, the antecedent of the implication is: $\neg \nabla D(x, \mathrm{~B}) \vee \neg \diamond D(x, \neg \mathrm{B})$. But by hypothesis, $\neg \nabla D(x, \mathrm{~B})$. So, we have $\neg F(x, \neg \mathrm{B})$.

Now, we can instantiate the general theorem just proved with a particular action, E, which is, by assumption, evil: $\neg \nabla D(x, \mathrm{E}) \rightarrow$ $\neg F(x, \neg \mathrm{E})$. However, by definition (7) we have:

(Conclusion) $\neg \nabla D(x, \mathrm{E}) \rightarrow \neg F^{\mathrm{M}}(x)$

This is a very important result: if an agent cannot perform an evil action, she is not meaningfully free with respect to it. By contraposition, we have found that if an agent is meaningfully free, then it is logically possible that she perform an evil action. It is worth noting that we have reached a result analogous to Plantinga's one with no commitment to puzzling metaphysical assumptions.

\subsection{Answering Mackie's Objection}

The result above does not answer yet Mackie's objection. The point, as we have seen before, is the following:

[T] here was open to him the obviously better possibility of making beings who would act freely but always go right (Mackie 1955: 209).

Indeed, the conclusion says that if someone is free then it is possible that she does wrong whilst Mackie's hypothesis concerns agents who are free and do not actually perform anything evil.

To answer this objection let us assume a number, $n$, of actual and possible free agents. We can assume, without problems, that the number of actual free agents is finite but the number of possible free agents 
infinite. Every actual free agent will make, in her life, a series of free and morally relevant choices: sometimes, she will choose the right action, sometimes the wrong one. We can assume possible agents will do the same, once actualized, with respect to their possible choices. Now let us suppose that God can know, for every agent $x$, the space of her possible choices. Let us indicate with $\mathrm{G}$ a right action and with $\mathrm{E}$ a wrong action. A possible world can be characterized by an array like this:

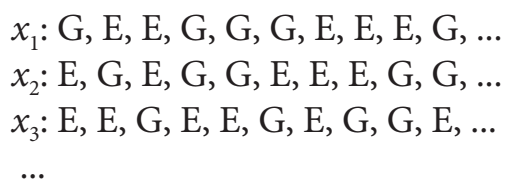

It matters neither how complex the array is nor if the choices are infinite. The crucial thing is the following: since we take into account possible agents and possible choices (besides the actual ones), it is rational to maintain that in this total space there will be all the infinite number of possible combinations. However, since there are all the combinations, we will expect at least one sequence of this kind: ${ }^{17}$

$$
x_{\mathrm{k}}: \mathrm{G}, \mathrm{G}, \mathrm{G}, \mathrm{G}, \mathrm{G}, \mathrm{G}, \mathrm{G}, \mathrm{G}, \mathrm{G}, \ldots
$$

To be more precise, it must be logically possible that at least one agent makes only right choices. If this is correct, we can reformulate Mackie's criticism in these terms: why doesn't God actualize $x_{\mathrm{k}}$ ? It is important to note firstly that for every good action of $x_{\mathrm{k}}$, it is possible that $x_{\mathrm{k}}$ does not do a good action and secondly that this is the guarantee of her real freedom.

The reason why God cannot actualize $x_{\mathrm{k}}$ is, very briefly, that God cannot know that $x_{\mathrm{k}}$ will perform this array before $x_{\mathrm{k}}$ makes this series of choices. God, being omniscient, knows the space of possible alternatives, but only when the agent has actually taken a decision does God know the choice of that agent and, therefore, which is the actual course of events.

We have previously ruled out that God has some form of middle knowledge: God cannot, on the basis of this alleged scientia media, actualize a world in which He knows that the agent, $x_{\mathrm{k}}$, will make only right choices, by creating a set of conditions, $\mathrm{S}$, in which $x_{\mathrm{k}}$ will always act rightly, since the conditions $\mathrm{S}$ always underdetermine $x_{\mathrm{k}}$ 's choices. ${ }^{18}$

\footnotetext{
${ }_{17}$ That a sequence like this is possible was noticed by Pike (1979).

${ }_{18}$ As we noted in 3.1, if $\mathrm{S}$ determined any of $x_{\mathrm{k}}$ 's choices, $x_{\mathrm{k}}$ would not be free in a compatibilist sense. In fact, by actualizing S, God would indirectly determine $x_{\mathrm{k}}$ 's choices.
} 
So God cannot actualize a state of the world which includes free agents who always do good actions since this world, though logically possible, is made not only by God's will but also by the free choices of agents.

One might object that, by denying divine foreknowledge of human actions, we are denying that God is omniscient. Actually, our view does not have this consequence. A being is omniscient if and only if he knows all true propositions (in formal terms $p \leftrightarrow \mathrm{K}(p)$ ). ${ }^{19}$ But we are not denying that if $x_{\mathrm{k}}$ performs the action, $\mathrm{A}$, God knows it. What we are denying is that God knows what $x_{\mathrm{k}}$ does because He actualizes a world, W, in which the maximal segment, $\mathrm{S}$, determines that $x_{\mathrm{k}}$ does $\mathrm{A}$. We state, on the contrary, that God knows that $x_{\mathrm{k}}$ does A because $x_{\mathrm{k}}$ does A.

One may object that, even if God's omniscience is preserved, nevertheless our position involves at least that God does not foreknow human decisions. Before $x_{\mathrm{k}}$ does A, God does not know that $x_{\mathrm{k}}$ will do A. As already noted in the paragraph 3.1, answering this objection is beyond the aim of this work. Nevertheless, we suggest that if God is outside time, then there is room to maintain that God atemporally knows that $x_{\mathrm{k}}$ does A just because $x_{\mathrm{k}}$ does it - at a certain time - and not because God actualizes a world where $x_{\mathrm{k}}$ does A.

\subsection{An Unlucky God}

What are the consequences of this view? We have seen that:

(i) Meaningful freedom involves the possibility of doing evil actions

(ii) Not even God can actualize people who always act rightly.

Therefore, we conclude that, whilst a world which contains free agents and no moral evil is logically possible, unfortunately, that is not our world. God actualized a world where free agents historically made wrong choices and God could not have foreseen that by any sort of middle knowledge, as we discussed above.

There are relevant differences with Plantinga's FWD: first of all, there is nothing similar to conditionals of freedom. These conditionals do not have a truth value and so they cannot be known either by God or by anyone else. Secondly, we don't make any appeal to the puzzling concept of transworld depravity: there is no metaphysical feature whereby

${ }^{19}$ More accurately, the left-to-right version, $p \rightarrow \mathrm{K}(p)$ would suffice: if a proposition is true, then it is known by God. The converse is true by the definition of knowledge. Things are different if the omniscience is defined in terms of belief; in that case, we should postulate both $p \rightarrow \mathrm{B}(p)$ and $\mathrm{B}(p) \rightarrow p$, i.e. that the God's beliefs are infallible. 
people, or free agents in general, must be corrupted in some way. On the contrary, we postulate that there exists a logically possible course of events where all people are perfectly good. If we maintain the distinction between a defence and a theodicy, our view is surely a defence: there is no contradiction between the existence of an omnipotent and perfectly good God and the presence of evil, since there exist free agents who choose, have chosen, and, very likely, will choose evil choices.

In this sense, evil is in no way a necessary feature of the world. It is a contingency, the outcome of the wicked choices of free agents. This distinguishes our proposal from any form of soul-making theodicy, where the existence of evil has a pedagogical and improving function for the human soul. The idea of an unlucky God, i.e. of a God who gambled on human beings and lost, could appear quite unusual and very far from the perfect being of classical philosophy of religion. However, the crucial point is the concept of freedom: on our view, if freedom is understood as the possibility of alternative courses of events, then that has a strong fall-out for the divine attributes.

There is a final objection we want take into account here: what good reason does God have to create free agents? This objection has been addressed to many free-will based approaches and it questions God's basic reason to create free agents. Indeed, if God foresees the evil in the world, why does he actualize beings which are going to suffer? Put in these terms, this objection does not concern our view since God knows that there is some evil only when men choose it and, therefore, He can recognize it only once it happens. ${ }^{20}$ One could retort that it is very likely that human beings, for instance, will do horrendous things and that caution is a value which God is supposed to have, inasmuch as $\mathrm{He}$ is morally perfect. ${ }^{21}$

However the role played by freedom here becomes essential to our case; often, it is stated that the existence of free agents is of such great value that it justifies God's risk. We want, however, to distinguish between freedom as an absolute value and freedom as an instrumental value towards the achievement of an absolute value. Mackie (1955) objected that if freedom were an absolute value, then its simple exercise

${ }^{20}$ From this, it follows that our thesis is compatible with the concept of divine Providence, provided that this is understood as an action of God directed against the evil done by men and assuming that this action is not conceived as the determining by God of human actions, since this determination would infringe human freedom.

${ }^{21}$ On this point cf. Perszyk (1998). 
would be a good, even if it is employed to do something bad. However, for our purposes, it is not necessary to endorse the thesis according to which freedom is an absolute value, rather it is sufficient to state that it is a necessary precondition for actualizing moral good (where, by moral good we mean a good state of affairs actualized by a free agent). In this sense, the existence of free agents, able to do evil as well as good, is a necessary precondition for the aim of moral good. Without freedom it is not, therefore, possible to actualize moral goods and, since freedom necessarily involves the possibility of evil, the creation of any moral good by a creature entails, necessarily, the possibility that that creature could do evil and thus fail to create moral good.

So, moral evil is the outcome of the actions of free agents. They can always possibly choose good; but they do not. The end of history is known by God only because the moral choices are effectively made and not before that. On the other hand, the creation of free agents is a necessary pre-condition for every moral good; therefore, the possibility of evil is a pre-condition for the creation of beings who do good things.

There is, however, another objection: why has God, who is morally perfect and omnipotent, created finite agents who can do bad things? Why cannot He alone actualize an infinite number of moral goods? It seems that the only way out would be to postulate a sort of limitation on God such that the achievement of certain goods can take place only by the necessary mediation of other free agents. However, this point is far beyond the scope of this work.

\section{BIBLIOGRAPHY}

Adams, R.M. 1973. 'Middle Knowledge', Journal of Philosophy, 70 (17): 552-554 Adams, R.M. 1977. 'Middle Knowledge and the Problem of Evil', American Philosophical Quarterly, 14 (2): 109-117

Craig, William Lane. 2001. 'Middle Knowledge, Truth-Makers, and the Grounding Objection', Faith and Philosophy, (18): 337-52

Gaskin, R. 1998. 'Middle Knowledge, Fatalism and Comparative Similarity of Worlds', Religious Studies, 34: 189-203

Mackie, J.L. 1955. 'Evil and Omnipotence', Mind, 64 (254): 200-212

MacFarlane, J. 2003. 'Future Contingents and Relative Truth', The Philosophical Quarterly, 53: 321-336

O'Connor, T. 1992. 'The Impossibility of Middle Knowledge', Philosophical Studies, 66: 139-166 
Øhrstrøm, P. 2011. 'Future Contingents', in Stanford Encyclopedia of Philosophy: $<$ http://plato.stanford.edu/entries/future-contingents/> [accessed 18/09/2013] Otte, R. 1987. 'A Defence of Middle Knowledge', International Journal for Philosophy of Religion, 21: 161-169

Perszyk, K.J. 1998. 'Free Will Defence With and Without Molinism', International Journal for Philosophy of Religion, 43 (1): 29-64

Pike, N. 1979. 'Plantinga on Free Will and Evil', Religious Studies, 15 (4): 449-473 Plantinga, A. 1967. God and Other Minds (Ithaca: Cornell University Press) Plantinga, A. 1974a. God, Freedom, and Evil (Grand Rapids: Eerdmans) Plantinga, A. 1974b. The Nature of Necessity (Oxford: Clarendon Press) Plantinga, A. 1985. 'Self-profile, in J.E. Tomberlin, and P. van Inwagen, (eds.) Self-profile. Alvin Plantinga (Netherlands: Springer), pp. 3-97

Pruss, A. 2003. 'A New Free-Will Defence', Religious Studies, 39 (2): 211-223

Thomason, R. H. 1970. 'Indeterminist Time and Truth Value Gaps', Theoria, 36: 264-281

Van Fraassen, B. 1966. 'Singular Terms, Truth-Value Gaps, and Free Logic', The Journal of Philosophy, 63 (17): 481-495

Zagzebski, L. 1991. The Dilemma of Freedom and Foreknowledge (Oxford: Oxford University Press) 